\title{
A APROPRIAÇÃO DA ILÍADA NA EPOPEIA VIRGILIANA ${ }^{1}$
}

\author{
Paulo Sérgio de Vasconcellos*
}

Recebido em: 22/03/2019

Aprovado em: 24/04/2019

RESUMO: Desde pelo menos Sérvio e Macróbio (século IV-V), costuma-se ver na estrutura da Eneida de Virgílio uma divisão em duas partes de acordo com o objeto de imitação homérico: a primeira constituiria uma espécie de Odisseia do protagonista Eneias (narrando seus errores, conforme Sérvio); a segunda, que narra gestas bélicas (de bello), sua Ilíada. Tem-se apontado que essa divisão não é estanque, havendo imitação significativa da Ilíada na primeira parte da Eneida e da Odisseia na segunda. Em 1989, num capítulo de seu Virgil's Augustan epic, Francis Cairns, em oposição à bipartição tradicionalmente aceita pelos estudiosos, defendia que a Eneida é estruturada como uma Odisseia com momentos iliádicos; mais recentemente, em 2012, em seu Virgil's Homeric lens, Edan Dekel apresentou uma espécie de versão mais refinada dessa interpretação, mostrando como a Ilíada comparece na Eneida mediada pela Odisseia. Neste artigo, voltaremos a essa questão para ressaltar a importância da Iliada na epopeia virgiliana. De forma sutil (rítmica, sonora, temática), a Ilíada já ecoa na proposição da Eneida, o que é significativo; a ira de Juno

\footnotetext{
${ }^{1}$ Há vinte e cinco anos atrás, Francesco Giancotti (1993, p. 2, n. 2) dizia: "A bibliografia virgiliana é tão vasta que, se é muito difícil, para não dizer impossível, poder se gabar de ter dela um conhecimento exaustivo, não é tampouco fácil conhecer dela, integralmente, campos específicos, sobretudo quando esses se desenvolveram através de vários séculos e em lugares diversos" ("La bibliografia virgiliana è talmente vasta che, se è molto difficile, per non dire impossibile, poterne vantare una conoscenza esauriente, non è nemmeno facile conoscerne interamente setori specifici, specie quando questi si siano sviluppati attraverso vari secoli e in sedi disparate”). Neste texto, praticamente só referenciaremos obras de fato citadas, já que, sobretudo a respeito da cena final da epopeia, a bibliografia é vastíssima. As traduções de textos latinos são de nossa lavra, exceto quando se indica explicitamente a autoria.
}

* Professor de Língua
e Literatura Latina,
Instituto de Estudos
da Linguagem,
Universidade Estadual
de Campinas. odoricano@gmail.com 
ecoa, como os estudiosos têm mostrado, a de Aquiles; ao final da epopeia, intertextualmente, o leitor é levado a projetar sobre Eneias a sombra de um Aquiles raivoso: esses dois momentoschave nos fazem refletir sobre a importância da Ilíada na apropriação de Homero por Virgílio e é esse aspecto da imitação virgiliana que destacaremos, como uma espécie de contraponto às análises que veem na Odisseia o modelo maior da Eneida.

PALAVRAS-CHAVE: Virgílio; Eneida; Homero; Ilíada; recepção.

\section{THE APPROPRIATION OF THE ILIAD IN THE VERGILIAN EPIC}

ABSTRACT: At least since Servius and Macrobius (IV-V a.D.), it is usual to see in the structure of the Aeneid a division into two sections according to the Homeric object of imitation: the first section would be a kind of Odyssey of the protagonist Aeneas (with the narrative of his errores); the second, which narrates his deeds in war (de bello), would be his Iliad. Scholars have pointed out that this division is not static, because there is also a significant imitation of the Iliad in the first section and of the Odyssey in the second. In a chapter of his 1989 Virgil's Augustan epic, Francis Cairns opposed the traditionally accepted bipartite structure by arguing that the Aeneid is structured as an Odyssey with iliadic moments. More recently, in his 2012 Virgil's Homeric lens, Edan Dekel presented a more sophisticated version of this interpretation, showing how the Iliad is filtered (in various ways) in the Aeneid by the Odyssey. In this article I return to this question to point out the crucial importance of the Iliad in the Vergilian epic. In a subtle way (through rhythm, sound, and themes), the Iliad has significant echoes in the proposition of the poem, and Juno's anger, as scholars have shown, echoes that of Achilles. At the end of the epic, readers are encouraged to see in Aeneas the shadow of an angry Achilles. These two key moments lead us to reflect on the importance of the Iliad in Vergil's appropriation of Homer, and I will highlight this aspect of the Vergilian imitation as a kind of counterpoint to the analyses that see the Odyssey as the major model of the Aeneid.

KEYWORDS: Virgil; Aeneid; Homer; Iliad; reception.

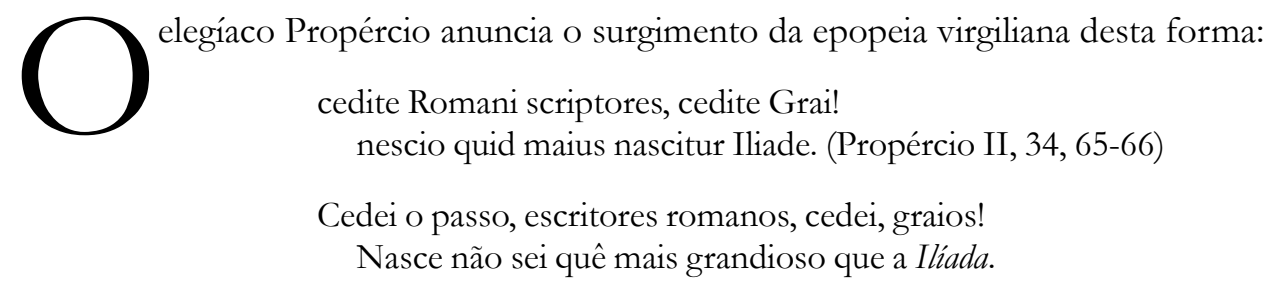

É interessante observar que Propércio anuncia um poema romano que há de superar a Ilíada e essa superação é expressa em imagem bélica, já que o verbo cedere pode ter o sentido de recuar, bater em retirada: ${ }^{2}$ a tradição épica é, significativamente, figurada como um embate

${ }^{2}$ Cf. a acepção 3 do verbete cedo no $O L D$. 
em que Virgílio derrotará seus competidores gregos e romanos. Note-se maius nascitur, que parece ecoar a apresentação do tema bélico no livro VII, 44-45, da Eneida: "maior rerum mihi nascitur ordo,/maius opus moueo" ("nasce-me maior série de coisas,/obra maior movo"); ${ }^{3}$ Virgílio anuncia o conjunto de temas iliádicos mais grandiosos que a matéria até então cantada em sua epopeia; Propércio reverbera a expressão, anunciando uma epopeia que, para o leitor que ainda não a conhecesse (como a maioria dos leitores virtuais do poema, em gestação naquela ocasião), pareceria uma imitação emulativa da Ilíada, não da Odisseia ou dos dois épicos homéricos.

Nessa mesma elegia, logo antes dos versos que destacamos, Propércio menciona ações bélicas da epopeia:

Actia Vergilium custodis litora Phoebi, [cf. Actia bella (Eneida, VIII, 675)]

Caesaris et fortis dicere posse ratis, [cf. Augustus Caesar (VIII, 678)]

qui nunc Aeneae Troiani suscitat arma

iactaque Lauinis moenia litoribus. [cf. Lauinaque.../litora...iactatus (I, 2-3)] ${ }^{4}$

Na tradução de Guilherme Gontijo Flores:

e que Virgílio cante o mar Ácio de Febo

guardião junto às fortes naus de César:

ele recorda as armas do Troiano Eneias

e os muros feitos em Lavínias praias.

Nos dois primeiros versos há um aceno sobretudo ${ }^{5}$ a uma passagem da descrição do escudo de Eneias no livro VIII e nos dois últimos à proposição da Eneida, a que se alude no destaque dado às arma e aos litorais lavínios, como se o elegíaco conhecesse ao menos o início da proposição da Eneida e o episódio do livro VIII. ${ }^{6}$ Os litorais de Ácio são mencionados nesse livro da epopeia e constituem um dos elementos da atualidade bélica romana incorporada na teia mítica da fábula da Eneida através do escudo de Eneias, em que aparece retratada em trecho relativamente longo (675-713), 39 versos, e com a indicação de que ocupa o centro (in medio, 675) do escudo do herói.

Propércio, portanto, menciona, ao saudar o advento da Eneida, matéria bélica da fábula mítica (extraída da primeira metade da Eneida) e matéria bélica da história romana contemporânea (da segunda metade da epopeia), sutilmente associando, aliás, César Augusto e

\footnotetext{
${ }^{3}$ Paralelo ressaltado por Heyworth (2009, p. 275).

${ }^{4}$ Todas as citações do original latino da Eneida seguem a edição de Conte (2011).

${ }^{5}$ Em seu Cynthia, Heyworth (2009, p. 275) aponta algumas outras passagens da Eneida (XI, 785; I, 258-259; III, 280; VII, 44-45) que ecoariam nos versos de Propércio. A nosso ver, os ecos mais fortes dizem mesmo respeito aos trechos dos livros I e VIII, que destacamos.

${ }^{6}$ De passagem, observamos que em "qui nunc Aeneae Troiani suscitat arma” se poderia ver elementos para apoiar a interpretação de "arma uirumque cano" como uma espécie de hendíadis: "as armas do varão" / "as armas do troiano Eneias”. Sobre esse incipit famoso, veja-se Conte (2012, p. 80ss.).
} 
Eneias, ao anunciar uma espécie de Ilíada romana destacando um personagem mítico-iliádico e o governante romano contemporâneo. O poeta elegíaco, portanto, estava ciente de que a nova epopeia combinaria mito e história recente; para nossa discussão, destacamos que seus versos fazem prever uma Ilíada romana.

Por outro lado, desde ao menos Macróbio e Sérvio (séc. IV-V) se repete a ideia de que a Eneida se estrutura em duas partes, de acordo com o modelo predominantemente imitado. ${ }^{7}$ Nas palavras deste último, os seis primeiros livros corresponderiam à Odisseia (nam primi sex ad imaginem Odyssiae dicti sunt - ad VII, 1) e os seis últimos à Iliada (bi autem sex qui sequunntur ad imaginem Iliados, ibidem), sem que isso signifique, como se sabe, restringir a matéria desses dois poemas às respectivas partes; assim, para dar um pequeno exemplo, jogos fúnebres iliádicos (já que imitam, sobretudo, os jogos em homenagem a Pátroclo, em Iliada XXIII) ocorrem no livro V da Eneida, ou seja, na parte que seria mais diretamente relacionada com a sua Odisseia. Iniciando com dois substantivos no acusativo, arma nirumque, Virgílio parece expressar desde o início o desejo de tratar de um duplo tema, ecoando em

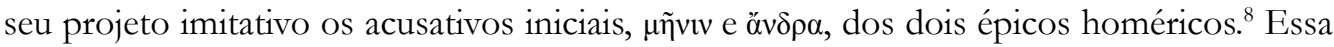
bipartição foi desafiada por importantes estudos; mais recentemente, em 2012, por Dekel, em seu Virgil’s Homeric lens. Já em 1989, num livro sobre a Eneida, Francis Cairns apresentava um capítulo intitulado "The Aeneid as Odyssey" (p. 177-214), em que defendia a tese de que a Eneida seria "não uma obra bipartida dividida pelo tema (i.e. viagens ou batalhas), mas uma Odisseia unitária com episódios iliádicos significativos" ("not a bipartite work divided by subject matter (i.e. voyages or battles), but an unitary Odyssey with significant iliadic episodes", p. 178). De imediato, o fato de Virgílio ter escrito a saga de Eneias e intitulado Eneida sua epopeia parece vinculá-la mais diretamente à saga de Odisseu. Propércio fazia prever uma Ilíada romana; para Cairns, trata-se de uma Odisseia com episódios iliádicos, sendo, pois, a Iliada, um modelo, nesse sentido, secundário.

Neste artigo, nós nos centraremos, sobretudo, em certas passagens do primeiro e do último livro da Eneida (posições no livro com forte valor programático) para defender a importância do modelo iliádico nessa epopeia e, assim, a estrutura bipartida, que, porém, a exemplo de tantos estudiosos, não consideramos de forma esquemática.

\footnotetext{
${ }^{7}$ Macróbio: "Iam uero Aeneis ipsa nonne ab Homero sibi mutuata est errorem primum ex Odyssea, deinde ex Iliade pugnas?" ("Quanto à própria Eneida, não tomou ela emprestado de Homero primeiramente o error da Odisseia, depois, da Iliada, os combates?”, Saturn. V, 2,6; ed. Marinone, 1987). Sérvio: "Nam prius de erroribus Aeneae dicit, post de bello" ("Pois primeiramente fala dos errores de Eneias, depois da guerra"; ed. Thilo-Hagen, v. 1, 1986, p. 6).

${ }^{8}$ Cf. Camps (1983, p. 24): "Muitos leitores sentem, no desenho métrico de arma virumque cano uma reminiscência da Ilíada em arma e um eco da Odisseia em virum, que corresponde ao óvo $\rho \alpha$ de Homero como protagonista humano do poema" ("Molti lettori sentono, nel disegno metrico di arma virumque cano, uma reminiscenza dell'Iliade in arma e un eco dell'Odissea in virum, che corresponde all' óv $\delta \rho \alpha$ di Omero come protagonista umano del poema").
} 
O elemento textual mais evidentemente apoiador de uma divisão da Eneida em duas partes $^{9}$ é a nova proposição do tema e invocação da musa Érato que aparecem no livro VII (37-45), significativamente não em seu começo, como se Virgílio desejasse evitar um esquematismo excessivo na divisão do conjunto:

Nunc age, qui reges, Erato, quae tempora rerum, quis Latio antiquo fuerit status, aduena classem cum primum Ausoniis exercitus appulit oris, expediam et primae reuocabo exordia pugnae. tu uatem, tu, diua, mone. dicam horrida bella, dicam acies actosque animis in funera reges Tyrrhenamque manum totamque sub arma coactam Hesperiam. maior rerum mihi nascitur ordo, maius opus moueo.

Eia, Érato! que reis no Lácio antigo, Qu'estado nesse tempo era o das cousas, Agora eu vou expor, quando o estrangeiro Exército aportou d'Ausônia às praias:

$\mathrm{E}$ a origem da primeira desavença Recordarei. Tu o teu vate, ó Diva, Tu inspira! Direi hórridas guerras, Exércitos direi, e reis levados Pela ira à morte, e os esquadrões Tirrenos, E toda a Hespéria em armas reunida.

Maior se me apresenta ordem de cousas, Mor empresa cometo. (Barreto Feio)

Como se sabe, a trama das guerras no Lácio joga com a expectativa de que a guerra de Troia se repita, e Juno parece contar com isso. ${ }^{10}$ A Sibila, no livro VI, chegara a anunciar um novo Aquiles para o Lácio (alius Latio...Achilles, VI, 89), e a questão, para o leitor, será saber se esse Aquiles será Turno ou Eneias. O próprio Turno se atribui esse papel. ${ }^{11}$ Mas o rútulo terminará seus dias no papel de Heitor, sacrificado por Eneias-Aquiles para vingar a morte de Palante-Pátroclo.

\footnotetext{
${ }^{9}$ Não tivemos acesso a um estudo de Stratis Kyriakidis que traz interessante elemento para a discussão sobre o uso dos modelos homéricos na Eneida: segundo Harrison (2001, p. 172-73), o autor defende que, quando Eneias e os seus homens navegam ao redor das terras de Circe (sem penetrar em seu reino, portanto), está-se simbolicamente apontando para o fato de que a segunda parte da epopeia, ao contrário da primeira, evitará temas da Odisseia.

${ }^{10}$ Cf. Most (2001, p. 154).

${ }^{11}$ Vejam-se as palavras confiantes de Turno: "Hic etiam inuentum Priamo narrabis Achillem" (IX, 742): “contarás a Príamo que aqui também se encontrou um Aquiles".
} 
A proposição e o livro I como um todo parecem fazer pender a balança para a preponderância da Odisseia. Virgílio segue o modelo desse último épico na apresentação geral do tema e na sua dicção (imitando, por exemplo, a iteração com variação de caso $\pi \circ \lambda \lambda \dot{\alpha}$, $\pi \circ \lambda \lambda \tilde{\omega} v$ em multum, multa) e no procedimento da narrativa in medias res. O próprio título, Aeneis, como dissemos, e a menção retardada do nome do protagonista (v. 21 na Odisseia; v. 92 na Eneida), ao passo que Aquiles já é mencionado no primeiro verso da Ilíada, também apontam para a Odisseia como modelo maior.

Em Virgílio, porém, nada é simples. Weber (1987) mostra como imitação sutilíssima da Iliada se faz presente logo nas primeiras palavras do poema. Assim, temos em arma uirumque cano - individualmente, um troqueu, um anfíbraco e um jambo, exatamente a mesma

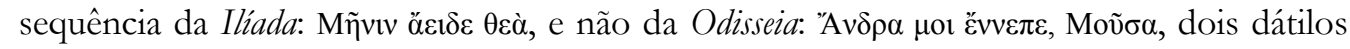
(considerando o pronome pessoal como parte de uma só palavra rítmica) e um troqueu. Além disso, em Virgilio a proposição ocupa sete versos, como ocorre na Ilíada. Depois desses sete versos, Virgílio trata das causas do rancor de Juno, assim como a Ilíada trata das causas da rivalidade entre Agamêmnon e Aquiles. Mais sutilmente, temos, sempre na análise de Weber, um sétimo verso na Eneida enfechando a proposição do tema que tem engenhosa relação com o sétimo verso da Ilíada:

Albanique patres atque altae moenia Romae.

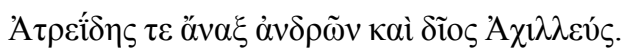

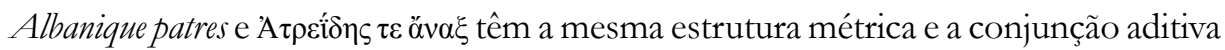
que vem da mesma palavra indoeuropeia. Sobretudo, ambos os versos terminam com nome próprio, que encerra a proposição, destacando-se, na Ilíada, seu protagonista e, na Eneida, a cidade cuja sombra paira sobre toda a epopeia virgiliana, a Roma que surgirá, séculos depois da fábula mítico-lendária, graças à ação de Eneias. Há outros elementos que se poderiam invocar, mas selecionamos esses para ilustrar como a imitação da Ilíada no início da Eneida pode estar presente de forma mais sutil que a mera reprodução de léxico comparável. ${ }^{12}$

Francis Cairns (1989, p. 193) afirma que "O prólogo da Eneida é, pois, inter alia, a afirmação de que a Eneida é uma Odisseia melhorada, Eneias, um Odisseu superior" ("The prologue of the Aeneid is thus inter alia a claim that the Aeneid is an improved Odyssey, Aeneas a superior Odysseus"). Mas essas palavras devem ser ao menos matizadas pelas considerações de Weber; além disso, é preciso dar a devida importância ao Eneias-Aquiles dos últimos livros, sobretudo da cena final, como os estudiosos têm apontado. O personagem de Eneias é mais ambíguo do que um "Odisseu aperfeiçoado", com seu perturbador lado Aquiles assomando ao final da epopeia, o ponto em que nos deteremos na segunda parte destas considerações.

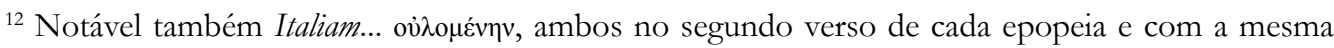
estrutura rítmica.
} 
Nossa contribuição mais pessoal, neste ponto, é a atenção que daremos a um aspecto da ação de Juno, tal como se depreende do seu primeiro discurso na epopeia, que é também o primeiro discurso da Eneida:

Vix e conspectu Siculae telluris in altum uela dabant laeti et spumas salis aere ruebant, cum Iuno aeternum seruans sub pectore uulnus haec secum: 'mene incepto desistere uictam nec posse Italia Teucrorum auertere regem? quippe uetor fatis. Pallasne exurere classem Argiuum atque ipsos potuit submergere ponto unius ob noxam et furias Aiacis Oilei? ipsa Iouis rapidum iaculata e nubibus ignem disiecitque rates euertitque aequora uentis, illum exspirantem transfixo pectore flammas turbine corripuit scopuloque infixit acuto; ast ego, quae diuum incedo regina Iouisque et soror et coniunx, una cum gente tot annos bella gero. et quisquam numen Iunonis adorat praeterea aut supplex aris imponet honorem?' (I, 34-49)

$\mathrm{Na}$ tradução de Barreto Feio:

Desavistando apenas a Sicília

Contentes para o alto velas davam, Co’as proas dividindo a salsa espuma:

Quando Juno, que no íntimo do peito

Conserva eterna chaga, só consigo

Dizia assim: Desistirei vencida

Da começada empresa? nem da Itália

Poderei afastar o rei dos Teucros?

Certo os Fados m’o vedam! Mas não pôde

Palas queimar a frota dos Argivos,

Submergi-los nas ondas, pela culpa

E frenesins d'um só, do Ajax de Oileu?

Ela mesma de Jove dardejando

Lá das nuvens o rápido corisco

As naus destrói, co'o vento empola os mares:

E ao mísero que flamas vomitava

Do roto peito, n'um tufão o toma,

E na ponta o cravou de agudo escolho.

E eu, que rainha os imortais precedo,

De Jove esposa e irmã, há tantos anos

Co'um só povo guerreio? Quem de Juno

Há de mais adorar a divindade,

Ou súplice ao altar vítima impor-lhe? 
É notável, nesse discurso de Juno, como a deusa parece atada ao passado iliádico. É como se Juno permanecesse presa à narrativa homérica, prolongando o combate contra Troia na sua ação contra Eneias e seus companheiros. A ação contra o troiano, que está na raiz das vicissitudes que adiam o cumprimento dos fados e permitem que a intriga da Eneida se desenrole como o faz, é apresentada no discurso de Juno como a continuação de uma empresa que não teria, assim, terminado na trama contada por Homero: enquanto Eneias estiver vivo, a guerra contra Troia deve prosseguir. Juno continua travando (gero) a guerra contra um só povo (una cum gente) começada há tantos anos (tot annos). ${ }^{13} \mathrm{~A}$ ação da deusa, então, projeta sobre o conjunto da epopeia virgiliana a narrativa da Ilíada. Lembremos que, na proposição, Virgílio menciona a memorem iram de Juno; no verso I, 23-24, reafirma essa condição, retratando-a ueterisque memor...belli, / prima quod ad Troiam pro caris gesserat Argis ("e lembrada da antiga guerra/que, por primeiro, junto a Troia travara por sua querida Argos"). Além disso, a memorem iram de Juno parece ecoar a $\boldsymbol{\mu \eta \tilde { v } \mathbf { v } . . . o u ̉ \lambda o \mu \varepsilon ́ v \eta v ~ d e ~ A q u i l e s ~ p o r ~ s e u ~ j o g o ~}$ comparável iram memorem. Juno é uma espécie de contrapartida divina de Aquiles e sua ira provoca os males dos troianos como a de Aquiles, na Ilíada, males sem conta para os gregos. Como diz Tarrant (2012, p. 5): "A ira de Juno contra os troianos é a força propulsora da trama da Eneida, assim como a ira de Aquiles o é para a Iliada" ("Juno's anger against the Trojans is the driving force of the Aeneid's plot, as the anger of Achilles is for the Iliad'). A associação é ainda mais estreita e sutil se aceitarmos que em Mene incepto, primeiras palavras do discurso ressentido da deusa, ecoa, anagramaticamente, a primeira palavra da Ilíada: men(e) in..., como apontado por William Levitan (1993). ${ }^{14}$ Depois de encontrarmos, nós próprios, um jogo sonoro na Eneida, ${ }^{15}$ tendemos a não hesitar em ver aqui uma alusão sutil, feita na teia fônica dos versos, à ira de Aquiles.

Destaquemos também que as causas da ira de Juno estão todas associadas ao passado troiano, remetendo, portanto, à Ilíada: o julgamento de Páris e a ofensa deste troiano à sua beleza (indicium Paridis spretaeque iniuria formae, I, 27); a estirpe odiosa e as honras dadas a Ganimedes (et genus inuisum et rapti Ganymedis honores, v. 28); além dessas causas fundadas no mito, o motivo menos pessoal e que recebe maior desenvolvimento (v. 19-22), o perigo que correria um dia sua amada Cartago, é apresentado em direta associação com o passado troiano, já que os romanos são retratados, da maneira vaga como a deusa conhece o porvir, como uma "progênie derivada do sangue troiano" (progeniem...Troiano a sanguine, v. 19).

A ideia de que a Eneida é uma Odisseia com momentos de Ilíada fica menos forte diante de um aspecto tão significativamente iliádico como a ira de Juno, mais ligada ao sentimento

\footnotetext{
${ }^{13}$ Poder-se-ia replicar que tot anos se refere aos anos anteriores ao começo da narração in medias res, e não aos embates da guerra de Troia. Notemos, contudo, que Juno fala em "guerras" (bella), o que nos pareceria impróprio para descrever sua ação contra Eneias nos episódios anteriores da Eneida, e que na introdução dos motivos do ódio de Juno o narrador usa a mesma expressão bellum gerere para se referir à guerra que Juno travara "junto a Troia por sua querida Argos" (ad Troiam pro caris... Argis, I, 24). ${ }^{14}$ Vejam-se as observações de O’Hara (1996, p. 115-16).

${ }^{15}$ Vasconcellos (2015, p. 125-29).
} 
vingativo de Aquiles do que ao de Possêidon contra Odisseu. Conforme vimos, Juno vê o combate a Eneias como uma luta engajada contra seu povo, isto é, como a continuidade da guerra narrada na Ilíada; nos versos 67-68, os troianos serão por ela designados como gens inimica que transporta Ilium e os vencidos penates para a Itália. No livro VII, quando Juno se sente indignada por não ter impedido que Eneias chegasse ao Lácio, a deusa expressa a sensação de uma derrota pessoal: nincor ab Aenea (VII, 310), deixando implícito que perdeu uma batalha, mas não a guerra. Quando, no livro XII, desiste, finalmente, da empresa, de modo que a trama da Eneida pode chegar a seu fim, emprega o verbo cedo, que, como já se recordou, pode ter conotação militar: cedo (XII, 618). ${ }^{16}$ Em suma, Juno se comporta como se, obsessivamente, jamais pudesse escapar de seu papel na trama da Ilíada e só desistirá dele quase ao final da epopeia. Sua ação contra Eneias é retratada em termos muito apropriadamente iliádicos: uma guerra pessoal contra Troia em que a deusa se ressente de ser derrotada; ao final da trama, ela expressa sua desistência também em termos bélicos, como um bater em retirada.

Quanto à visão de Eneias como um “Odisseu” aperfeiçoado, no entender de Cairns, deve ser contrastada com uma leitura da cena final da Eneida que esteja mais aberta às ambiguidades que ela faz aflorar. $\mathrm{Na}$ segunda parte da epopeia, como vários estudiosos têm mostrado, Eneias surge como um novo Aquiles, dotado de um furor vingativo que, de forma perturbadora, o associa a sua grande inimiga divina Juno.

Antes de analisar essa cena, observemos que o livro final da Eneida parece-nos apresentar ao menos três blocos temáticos que representam uma retomada de temas do primeiro livro, ou seja, uma tripla composição anular ou três elementos que demonstram esse tipo de estruturação da narrativa: 1. Turno retratado como o Eneias da primeira aparição do herói; 2. alusivamente, eco da saga de Diomedes num episódio do último livro (a pedra que Turno não consegue atirar em Eneias, XII, 896-907, contrastando com a ação de Diomedes, que, na Ilíada, fere Eneias com uma pedra e quase o mata, V, 302-310), reverberando o desejo de Eneias de ter morrido às mãos daquele herói iliádico (I, 96-98); 3. a fúria de Juno ecoando na fúria de Eneias contra seu inimigo na cena final, nos dois casos havendo como móvel uma lembrança penosa (no caso de Eneias, a morte de Palante trazida à tona pela vista do boldrié do jovem que Tuno portava). Esses três blocos temáticos remetem à saga da Ilíada; vamos examiná-los brevemente a seguir. ${ }^{17}$

\footnotetext{
${ }^{16}$ Veja-se, contudo, Johnson (1976, p. 123-127) sobre as ambiguidades dessa suposta capitulação total de Juno; veja-se, também, na p. 130: “O poema termina, pelo menos em um nível, com o triunfo de Juno" ("The poem ends on one level at least, with the triumph of Juno").

${ }^{17}$ Há outros elementos associando os livros I e XII e apoiando, assim, a ideia de uma estrutura anular. Apontamos um deles: no livro I, para assegurar a seu filho que os companheiros estavam bem, Vênus aponta para doze cisnes aos quais a "ave de Jove (Ionis ales, 394)" perturbava (turbabat, 395) e que conseguiam descer a terra em segurança (395-396). No livro XII, para atrapalhar a trégua firmada entre Eneias e Latino, Juturna mostra aos rútulos um prodígio: a "ave de Júpiter" (Ionis ales, 247, na mesma posição no verso) perseguia aves e se apoderou de um cisne; as outras aves se reúnem e investem unidas contra o agressor, que deixa cair a presa e foge (251-256). Na interpretação de Vênus, disfarçada sob a aparência de uma virgem caçadora, os cisnes do primeiro prodígio são os troianos;
} 
No final da epopeia, ${ }^{18}$ Turno é retratado na mesma situação desesperadora do Eneias do primeiro livro (sobretudo, o eco ast illi soluuntur frigore membra, XII, 951/exemplo Aeneae soluuntur frigore membra, I, 92). Um outro elemento que conecta as duas situações, como se a epopeia terminasse numa ring-composition em que os personagens se invertessem na situação similar, pode ser detectado no episódio da pedra que Turno tenta lançar em Eneias (XII, 896-907). Como os estudiosos demonstraram, o modelo principal para essa cena de uma pedra usada como arma é Iliada V, 302-310. Nessa cena homérica, Diomedes lança uma pedra em Eneias, ferindo-o, e o herói só escapa da morte por causa da intercessão de Afrodite. $\mathrm{Na}$ primeira aparição de Eneias aos leitores da Eneida, ele se lamenta por não ter morrido às mãos do mais bravo dos gregos, Diomedes:

o Danaum fortissime gentis

Tydide, mene Iliacis occumbere campis

non potuisse tuaque animam hanc effundere dextra (I, 96-98)

Ó da gente dos Dânaos o mais bravo,

Tidida, não poder eu nos campos ilíacos

ter sucumbido e exalado esta minha alma à tua destra!

Eneias deseja não ter sobrevivido aos embates com Diomedes. No final da Eneida, essa cena é novamente ecoada, mas agora Turno parece assumir o papel que fora de Diomedes. Tenta repetir a agressão... sem sucesso, um Diomedes falho, pois. No início e no fim da epopeia, um momento-chave da saga de Eneias na Ilíada - momento crítico em que quase morreu, mas ao mesmo tempo um momento que revela ser ele protegido por uma deusa - é ecoado. Acrescentemos, contudo, que as relações intertextuais em Virgílio são sempre complexas; ao episódio homérico evocado se deve acrescer a cena em que o próprio Eneias lança uma pedra sobre Aquiles (XX, 285-287): ${ }^{19}$ aqui, Eneias parece desempenhar o papel

na de Juturna, disfarçada sob a aparência de um áugure, os cisnes são os que Eneias persegue. A correlação não é perfeita, já que a águia do primeiro prodígio não pode ser associada a um inimigo específico, ao passo que no segundo é Eneias; mas chama a atenção que as possíveis vítimas da águia, que, porém, escapam, no primeiro caso sejam os troianos e no segundo, os inimigos dos troianos. Cf. Putnam (1965, p. 166). Se pensarmos que os troianos, no livro I, encontram-se na situação em que estão por causa de Juno, a deusa estaria por detrás da imagem da águia; no livro XII, segundo a interpretação dos seus inimigos... Eneias: mais uma instigante associação entre o herói e sua inimiga divina a acrescentar às que a crítica têm apontado. Há outros ecos verbais associando os dois passos, que, porém, não podemos apontar e discutir aqui.

${ }^{18}$ É notório o desconforto que a cena final provoca em muitos leitores; como diz Johnson (1976, p. 115): "Não é segredo que haja uma insatisfação geral ou um desconforto com esse desfecho famoso" ("It is no secret that there is a general dissatisfaction or uneasiness with this famous closure").

${ }^{19}$ Ver Boyd (2002, p. 83). 
que fora de Diomedes, servindo essa cena, portanto, de modelo para a inversão de papéis em que Turno substitui Diomedes. ${ }^{20}$

Na cena final, contrariando a prescrição que seu pai Anquises dirigira ao "Romano" (que ainda não nascera mas adviria da ação de Eneias) no sentido de "poupar os vencidos e debelar os soberbos": parcere subiectis et debellare superbos, VI, 853), ${ }^{21}$ Eneias mata o inimigo ferido e submisso, que tinha reconhecido a vitória do troiano (nicisti, XII, 936). Turno pede pela vida ou, se Eneias preferisse, pelo retorno de seu corpo sem vida aos seus: et me seu corpus spoliatum lumine mauis/ redde meis (XII, 935-6), que faz evocar diante do leitor que lê a epopeia pela primeira vez dois comportamentos diferentes de Aquiles que Eneias poderá reviver: a morte do inimigo, em ato de vingança (como Aquiles vingando Heitor), e a entrega de seu cadáver, em ato de abrandamento da ira (como Aquiles, ao final da Ilíada, devolvendo a Príamo o corpo do filho). ${ }^{22}$ Mas Eneias pode também poupar o inimigo, pois Turno, ao contrário de Heitor, não fora ferido mortalmente. O dilema aqui, próprio da Eneida, está no fato de que, para cumprir o que prometera ao pai do jovem Palante, Eneias deve matar o inimigo, que, porém, reconhecera sua derrota com humildade, não soberba. Se Eneias poupasse o inimigo suplicante, seguindo as palavras de Anquises, quebraria um padrão comportamental do guerreiro iliádico, já que na Ilíada não se poupa o suplicante vencido no duelo (Barchiesi, 2015, p. 85). O último papel de Eneias é o de Aquiles raivoso e o texto salienta essa fúria, terminando sem narrar o que poderia ser um final mais conciliador e na linha do final da Ilíada. Eneias comparece pela última vez diante do leitor tomado de ira:

furiis accensus et ira/terribilis (XII, 946-947)

${ }^{20}$ Cf. Lyne (1992, p. 134-35): "Assim, enquanto Turno se vê como um potencialmente bem sucedido Diomedes, Virgílio o apresenta como um Diomedes inapropriado e derrotado (tudo isso enquanto se sucedem as alusões a Eneias-Aquiles/Turno-Heitor), e o processo de comparação e contraste é realizado para nós (...). Desespero derrotista envolvendo Diomedes é transformado em vitória envolvendo 'Diomedes") ("So while Turnus sees himself as a potentially successful Diomedes, Vergil presents him as a discomfited and defeated Diomedes (all this while the Aeneas-Achilles/TurnusHector allusions progress), and the process of comparing and contrasting is done for us (...) Defeatist despair involving Diomedes is turned into victory involving 'Diomedes"').

${ }^{21}$ Cf. Putnam (1965, p. 193): "Ele [Eneias] esquece o que seu pai definia como a grande missão de Roma (VI, 851-53)" ("He loses sight of what his father defined as Rome's grand mission (VI, 851-53)"). Que Anquises se dirija explicitamente ao "Romano", e não a seu filho, não resolve a questão: Eneias encarna virtudes que serão caras aos futuros romanos. Assim, esperar-se-ia que o herói arquetípico obedecesse ao preceito do pai; o personagem, porém, na cena final da epopeia, é colocado numa situação ambígua, como no episódio de Dido, em que se vê compelido a fugir de Cartago e, de certa forma, trair a fides com relação a Dido para cumprir as ordens de Júpiter.

${ }^{22}$ Cf. Barchiesi (2015, p. 91): "Na hesitação de Eneias convivem, antes do desfecho narrativo, o vestígio do Aquiles vingador de Ilíada 22 e aquele, menos previsível, mas claramente pressuposto pelo texto, do Aquiles clemente de Ilíada 24" "In Aeneas's hesitation coexists, before the narrative cuts out, the track of Achilles the avenger from Iliad 22 and, less predictably but clearly presupposed by the text, the track of merciful Achilles from Iliad 24.”). 
Esse furor é provocado pela vista do boldrié de Palante, que Turno leva aos ombros como presa de guerra e que traz à tona a dor "feroz" de Eneias: saeni monimenta doloris (946). Como Juno, Eneias lembra de algo que provoca dor profunda e que motiva sua ação retaliadora. No começo da epopeia, o narrador se indaga sobre o motivo da dolor de Juno: quidue dolens (I, 9). Na exposição das causas do ódio profundo da deusa aos troianos, Virgílio menciona os saenique dolores (I, 25) e representa a deusa inflamada de ódio pelos motivos apontados: his accensa super (29). A atribuição do adjetivo saeuns a dolor, duas palavras individualmente muito frequentes na Eneida, só ocorre justamente no começo da epopeia, em que o sintagma é aplicado a Juno, e no fim, aplicado a Eneias. Curiosamente, ao dar suas recomendações ao Romano, Anquises emprega o verbo memento: "Lembra-te". ${ }^{23} \mathrm{Na}$ cena final, Eneias terá uma lembrança dolorosa semelhante à de Juno, que provoca, como reação, ódio $;^{24}$ o herói não lembrará a recomendação paterna de poupar os submissos. Mais uma associação textual com Juno ocorre na reação de Eneias à súplica do inimigo: Stetit acer in armis (XII, 938), que lembra a expressão aplicada a Juno quando ela avista os troianos se estabelecendo tranquilamente no Lácio: stetit acri fixa dolore (VII, 291). Aliás, Acer é um dos adjetivos que Horácio, na Arte Poética, 121, aplica ao ethos tradicional de Aquiles.

Ironicamente - uma ironia trágica - Eneias é tomado de furor quando sua inimiga divina justamente acabara de renunciar ao furor. No discurso em que convence Juno de desistir de sua ação contra os troianos, Júpiter a incita: uerum age et inceptum frustra summitte furorem (832): "Eia, vamos!, contém um furor intentado em vão". Essa fala de Júpiter se inicia com as palavras com que Tétis incita Aquiles a aceitar o resgate pelo corpo de Heitor:

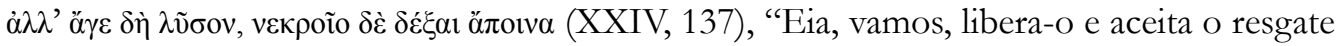
pelo morto". Juno desiste de sua fúria; momentos depois, Eneias pratica seu ato de fúria vingativa... Além disso, como observa Tarrant (2012, p. 296), Júpiter afirma seu veto a que Juno prossiga em sua ação com palavras que ecoarão naquelas com que Turno tentará demover Eneias de prosseguir em seu ódio: ulterius temptare ueto (XII, 806)/ulterius ne tende odiis (XII, 938). Ao desistir de seu rancor iliádico, Juno permite que ocorra finalmente o embate entre Eneias e Turno e o desfecho da epopeia com uma cena iliádica, pois que ecoa fortemente o combate entre Aquiles e Heitor. ${ }^{25}$

\footnotetext{
${ }^{23}$ Cf. Most (2001, p. 152).

${ }^{24}$ Cf. Seider (2013, p. 189): “Ambos, mortal e deusa, irrompem em violência raivosa por causa de suas memórias [...] eles reagem à memória com emoções fortes e são essas emoções que, por sua vez, desencadeiam uma resposta violenta" ("Both of them, mortal and goddess alike, strike out in angry violence because of their memories [...] they react to memory with strong emotions and it is these emotions which in turn prompt a violent response"). Seider, porém, nota a diferença entre a cólera recorrente e autoalimentada da deusa e o acesso de furor de Eneias, motivado pela lembrança pontual da morte de Palante e a necessidade de vingá-la em nome do pai do rapaz. Seja como for, permanece forte o paralelismo entre os dois personagens, apoiado por ecos verbais.

${ }^{25}$ A respeito de outras camadas alusivas que podem estar operando na cena final (com alusões inclusive a momentos da história romana e a combates de gladiadores), ver Hardie (1989, p. 147-56).
} 
Abramos um parêntese para apontar algo curioso, que envolve, na tradução da Eneida, uma questão de interpretação de sua cena final: Manuel Odorico Mendes, ao traduzir um verso da passagem, justamente o do golpe fatal que Eneias inflige em Turno, enuncia um jogo fônico, um criptograma quase perfeito do nome de Aquiles:

No peito aqui lhe esconde o iroso ferro, AQUILH(E)ES...

Pode ser simples coincidência, o que, porém, seria estranho num tradutor que está sempre muito atento aos sons dos versos. Seja como for, de forma consciente ou inconsciente, o tradutor parece ter assinalado nos sons da tradução uma certa interpretação da ação de Eneias. Odorico, além disso, caracteriza o ferro da espada como "iroso", em interessante hipálage, destacando, assim, o sentimento do troiano no ato vingador. Não se teria, pois, na cena final da epopeia, nenhum "Odisseu aperfeiçoado", mas um perturbador Aquiles enraivecido, um Eneias se comportando de forma muito parecida com sua inimiga divina desde a Ilíada.

Por fim, a Eneida termina com uma cena que ecoa cena célebre da Ilíada; seu último verso (XII, 952) repete o que fora empregado no episódio da morte de Camila (XI, 831), assim como na Ilíada versos semelhantes são empregados duas vezes, na morte de Pátroclo (XVI, 856-857) e na de Heitor (XXII, 362-363):

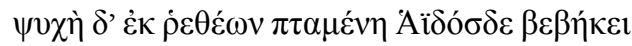

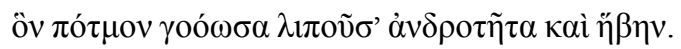

A psiquê

voou-lhe dos membros para o Hades, chorando o fado que lhe tirou vigor e juventude. (Haroldo de Campos) ${ }^{26}$

A última fala de Eneias se abre com palavras que recordam as primeiras palavras de Juno na epopeia e que já mencionamos; compare-se:

terribi/ lis: 'tune hinc spoliis indute meorum (...)' (XII, 947)

haec se/cum: 'mene incepto desistere nictam (...)' (I, 37)

Cf. tun(e)hinc/men(e)inc- na mesma posição no verso!

\footnotetext{
${ }^{26}$ Observe-se que Haroldo de Campos não mantém aqui a dicção formular, já que na primeira ocorrência dos versos a tradução é diversa: "A psiquê se evolou dos seus membros. Baixou/ ao Hades deplorando a juventude e a força./ perdidas." O tradutor procede como Odorico Mendes, que também prefere a variação, traduzindo de forma diversa: "dos membros desatada/A alma voa aos infernos lamentando/O seu viril esforço e mocidade” (XVI, 726-728); “a Plutão baixa/A alma dos membros solta, a lamentá-lo/Murcho em flóreo vigor da mocidade” (XXII, 292-294).
} 
A crítica já notara a semelhança entre mene e tune iniciando os dois discursos diretos; $;^{27}$ quanto a nós, chamamos a atenção para que a semelhança formal é um pouco maior.

Em resumo, a epopeia virgiliana termina evocando célebre cena da Ilíada, com Eneias tomado do furor vingativo de Aquiles, ao qual se sobrepõe o de Juno; ao matar o inimigo suplicante, o troiano segue um padrão que remete ao código de comportamento da Ilíada. Não há cena final apaziguadora, equivalendo ao abrandamento de Aquiles na cena do resgate do corpo de Heitor e seus funerais ao final da Ilíada (ou a concórdia estabelecida entre Odisseu e os parentes dos pretendentes por ele mortos, cena final da Odisseia). Assim, Eneias aparece pela última vez ao leitor como Aquiles ou Juno vingativa, ${ }^{28}$ sem nenhum decréscimo da tensão ao final do discurso épico.

Nossa intenção neste artigo não foi argumentar contra a teoria de Francis Cairns, defendendo o modo como tradicionalmente se divide a Eneida em duas partes. O objetivo era ressaltar a importância crucial da Ilíada na Eneida em face da Odisseia e ao mesmo tempo indicar como a epopeia virgiliana, complexa sob qualquer ângulo, também o é na questão do uso dos modelos homéricos em sua estruturação. Em suma, nesta e em outras questões, é sempre arriscado apresentar uma interpretação da Eneida que não se pretenda senão uma espécie de tateio provisório em terreno fluido. Em vez de respostas definitivas, cada nova análise parece suscitar novas questões. Em todo caso, esperamos ter cumprido nosso principal objetivo: mostrar como a Ilíada não pode ser considerada um modelo secundário com relação à Odisseia para a interpretação da estrutura compositiva da Eneida.

\section{REFERÊNCIAS}

BARCHIESI, Alessandro. Homeric effects in Vergil's narrative. Tradução de Ilaria Marchesi e Matt Fox. Princeton: Princeton University Press, 2015. Originalmente em italiano: La traccia del modelo. Effetti omerici nella narrazione virgiliana. Pisa: Giardini, 1984.

BOYD, Barbara Weiden. Tum pectore sensus vertuntur varii: reading and teaching of the end of the Aeneid. In: ANDERSON, William S.; QUARTARONE, Lorina N. (Ed.). Approaches to teaching Vergil's Aeneid. New York: The Modern language Association of America, 2002, p. 80-86.

CAIRNS, Francis. Virgil's Augustan epic. Cambridge: Cambridge University Press, 1989.

CAMPOS, Haroldo de. Ilíada de Homero. São Paulo: Mandarim, 2001.

${ }^{27}$ Cf. O’Hara (2010, p. 105): “O tune de Eneias no começo de seu discurso, 12, 947, corresponde ao mene de Juno no começo de sua primeira linha" ("Aeneas' tune at the start of his speech, 12. 947, corresponds to Juno's mene at the start of her first line, 12. 952").

${ }^{28}$ Cf. Putnam (1965, p. 162: "Se o livro XII retrata a tragédia de Turno, também delineia a gradual submissão de Eneias ao singular furor de Dido" ("If Book XII depicts the tragedy of Turnus, it also delineates the gradual submission of Aeneas to the particular furor of Dido"...). Mais que o de Dido, o furor de Eneias ecoa o de Juno. 
CAMPS, Anthony. Lettura del primo libro dell'Eneide. In: GIGANTE, Marcello (Ed.). Lecturae vergiliane. L'Eneide. Napoli: Giannini, 1983.

CONTE, Gian Biagio (Ed.). Memoria dei poeti e sistema letterario. Palermo: Sellerio, 2012.

CONTE, Gian Biagio. P. Vergilius Maro. Aeneis. Berlin: De Gruyter, 2011.

FEDELI, Paolo (Ed.). Propertius. Stuttgart: Teubner, 1994.

FLORES, Guilherme Gontijo (Org.). Elegias de Sexto Propércio. Belo Horizonte: Autêntica, 2014.

GIANCOTTI, Francesco. Victor tristis. Lettura dell'ultimo libro dell' Eneide. Bologna: Pàtron, 1993.

GRUMMOND, W. W. de. Saevus dolor: the opening and the closing of the 'Aeneid'. Vergilius, v. 27, p. 48-52, 1981.

HARDIE, Philip R. Virgil's Aeneid. Cosmos and imperium. Oxford: Clarendon Press, 1989.

HARRISON, Stephen. Some generic problems in Horace's Epodes. In: CAVARZERE, Alberto; ALONI, Antonio; BARCHIESI, Alessandro (Ed.). Iambic ideas. Essays on a poetic tradition from archaic Greece to the late Roman empire. Lanham: Rowman \& Littlefield, 2001, p. $172-73$.

HEYWORTH, Stephen J. Cynthia. A companion to the text of Propertius. Oxford: Oxford University Press, 2009.

HOMERO. Ilíada. Tradução de Odorico Mendes. Prefácio e notas de Sálvio Nienköter. Cotia: Ateliê; Campinas: Unicamp, 2008.

JOHNSON, W. R. Darkness visible. A study of Vergil's Aeneid. Berkeley: University of California Press, 1976.

LEVITAN, W. Give up the beginning? Juno's mindful wrath (Aeneid 1.37). Liverpool Classical Monthly, v. 18, p. 1-15, 1993.

LYNE, R.O.A.M. Further voices in Vergil's Aeneid. Oxford: Clarendon Press, 1992.

MARINONE, Nino (Ed.). I saturnali di Macrobio Teodosio. Torino: UTET, 1987.

MOST, Glenn W. Memory and forgetting in the Aeneid. Vergilius, v. 47, p. 148-70, 2001.

O'HARA, James. True names. Vergil and the Alexandrian tradition of etymological wordplay. Ann Arbor: The University of Michigan Press, 1996.

O'HARA, James. The Unfinished Aeneid? In: FARRELL, Joseph; PUTNAM, Michael C. J. (Ed.). A companion to Virgil's Aeneid and his tradition. Malden: Wiley-Blackwell, 2010, p. 96-106.

PUTNAM, Michael. The poetry of the Aeneid. Cambridge, MA: Harvard University Press, 1965.

SEIDER, Aaron M. Memory in Vergil's Aeneid. Creating the past. Cambridge: University Press, 2013. 
TARRANT, R. (Ed.). Virgil Aeneid Book XII. Cambridge: University Press, 2012.

THILO, Georg; HAGEN, Hermann (Ed.). Servii grammatici qui feruntur in Vergilii carmina commentarii. Hildesheim: Georg Olms, 1986. v. 1.

VASCONCELLOS, Paulo Sérgio de. A sound play on Aeneas' name in the Aeneid. A brief note on VII.69. Vergilius, v. 61, p. 125-29, 2015.

VIRGÍLIO. Eneida. Traduzida por Barreto Feio e José Maria da Costa e Silva. São Paulo: Cultrix, 2004.

WEBER, Clifford. Metrical Imitation in the proem of the Aeneid. Harvard Studies in Classical Philology, v. 91, p. 261-71, 1987. 